\author{
Ewelina Kwiatkowska \\ Dr inż. / prawnik \\ Politechnika Wrocławska, Katedra Mostów i Kolei \\ kwiatkowskae@interia.pl

\section{Wiesław Fiebig} \\ Dr hab.inż. \\ Politechnika Wrocławska, Wydział Mechaniczny \\ Wieslaw.fiebig@pwr.edu.pl
}

DOI: 10.35117/A_ENG_18_05_01

\title{
Influence of the use of spring vibration isolators in the construction of track pavement for damping vibrations from the track
}

\begin{abstract}
The paper presents tuned track bed vibration isolation systems used for the railway and tramway lines. The presented solution based on mass spring systems and is effective especially at lower frequencies. The tuning frequency of such systems is mostly in the range 5 to $8 \mathrm{~Hz}$. With measures based on spring elements elaborated by GERB company the significant vibration and noise reduction coming from the railways and tramways can be achieved. This new technology in Poland can be used during the track structure modernization as well as in the new projects, in which the track bed vibration isolation is required.
\end{abstract}

Keywords: Spring vibration isolators; Damping of track pavement

\section{Introduction}

The rail road located in urbanized areas requires the use of anti-vibration protection in the construction of the railway surface. The Polish railway market uses bedding and non-bedding surfaces. In order to reduce vibrations, anti-vibration mats are used in the bedding surface. In non-heap surfaces, in order to reduce vibrations, vibro-isolation is used under a concrete slab, under a block support using rail fastening with block supports, in a non-pile surface with a rail in the lagging, the lagging mass of the rail is a vibro-insulating material.

This article is devoted to the previously unused in Poland structural solution of track surface which is the rail surface, which is equipped with spring vibro-isolators. Surface with spring vibration isolation has been used for 30 years in European and Asian countries. The article presents different types of spring vibro-isolators used in bedding and non-bedding surface as well as the results of research on the impact of using spring-loaded vibro-isolation in a non-heap surface on the damping of track-side vibrations.

\section{The principle of vibro-isolation}

The principle of vibro-isolation is illustrated in Fig. 1. The vibration transmission depends on the ratio of the frequency of the forcing force to the resonant frequency. 


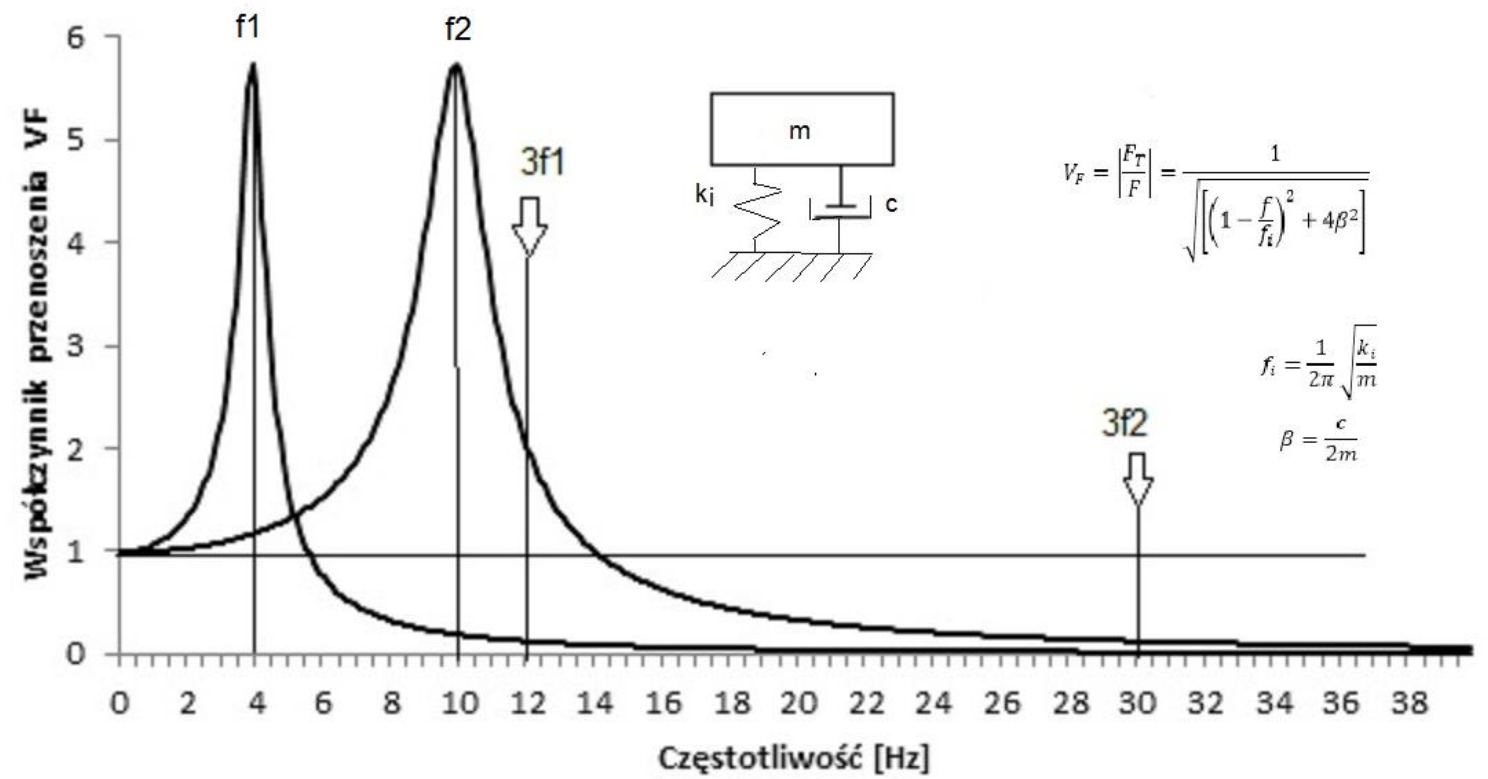

1. The principle of vibro-isolation

Fig. 1 shows the vibrations transmission function at two different stiffnesses of the k1 and i substrates $\mathrm{k} 2(\mathrm{k} 2>\mathrm{k} 1)$. Resonance frequencies $\mathrm{f} 1$ and $\mathrm{f} 2$ correspond to these two types of substrate. If the vibroisolation system has a higher stiffness, it has a higher resonant frequency at the same mass. For the vibroisolation system with a resonance frequency f1, the so-called effective vibration isolation (> 87\%) occurs at frequencies 3 times higher than the resonance frequency f1. The effectiveness of the vibroisolation of the system with a higher resonant frequency is definitely lower, especially in the low-frequency range. The lower the resonance frequency, the higher the efficiency of the vibroisolation system. In the case of spring vibroisolation, resonant frequencies of 5 to $6 \mathrm{~Hz}$ can be obtained, which cannot be achieved with solutions based on vibroinsulation mats.

\section{Spring vibro-isolators in a non-heap surface}

A railway type of ballast and non-bed type can be equipped with vibration isolation in the form of a system of springs mounted under a concrete slab or concrete bed. Currently spring vibro-isolators are used on railway, tram and meter lines to reduce the vibrations generated by the train and transferred to buildings in the vicinity of the rail road.

There are three types of vibro-shock absorbers, which, due to the number of springs, are divided into single-stroke GSI, single-spring type EBS, two- or three-spring type KY Fig. 2 .

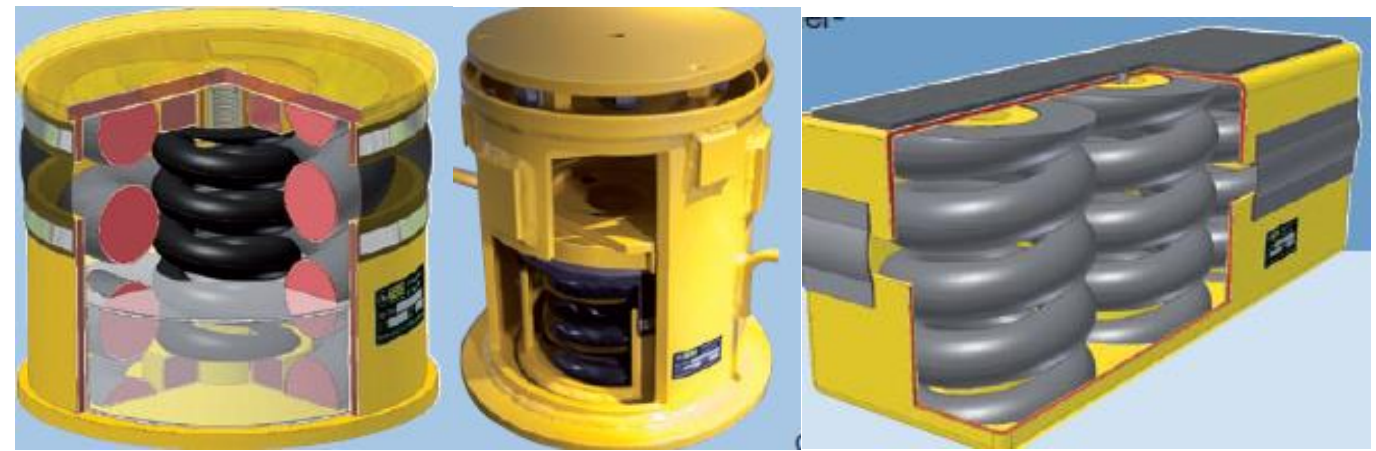

2. Types of springs from the left: EBS, GSI, KY 
Stiffness of the vibro-shock absorber springs can be individually selected in the vertical and horizontal direction. Changing the stiffness of the vibro-shock absorbers gives the possibility to design and perform vibroisolation tailored to the needs of the investment.

of:

GERB GSI single-vibration isolators are available in stiffness variants in the direction

- vertical in the range:5,42-4,52 kN/mm,

- horizontal in the range $6,92-3,46 \mathrm{kN} / \mathrm{mm}$.

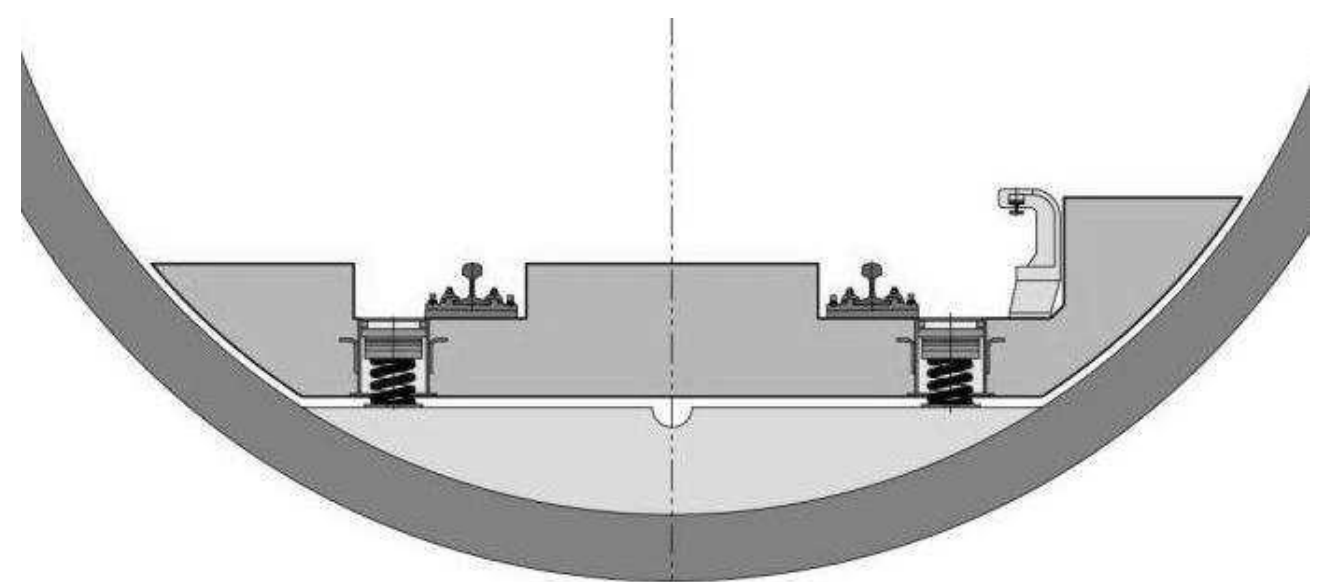

3. GSI vibro-isolators in the undersuspended rail surface (GERB).

Two-spring vibro-shock absorbers KY fig. 4 are offered with a coefficient of elasticity in the direction of:

- vertical in the range $10,84-13,26 \mathrm{kN} / \mathrm{mm}$,

- horizontal in the range $13,83-9,86 \mathrm{kN} / \mathrm{mm}$.

Three-spring vibro-shock absorbers KY fig. 4 are offered with a modulus of elasticity in the direction:

- vertical in the range $16,26-19,88 \mathrm{kN} / \mathrm{mm}$,

- horizontal in the range $26,76-14,79 \mathrm{kN} / \mathrm{mm}$.

Spring-loaded vibration dampers can be used in the dirt-free surface fig. 4 and under the concrete channel in the construction of the ballast surface fig. 5 .

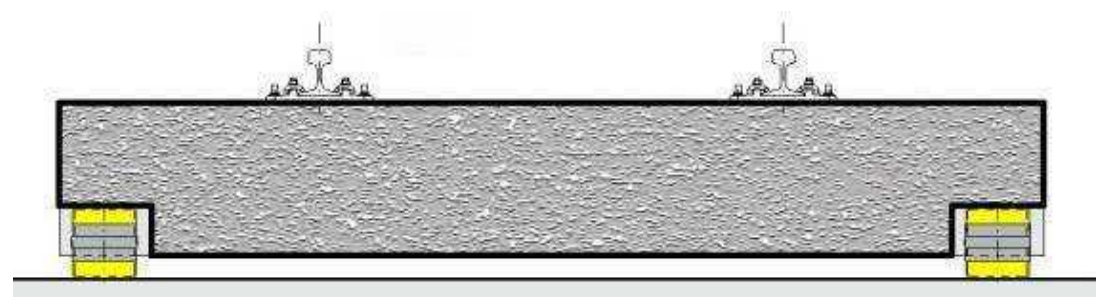

4. KY vibro-isolators in the undamaged rail surface (GERB) 


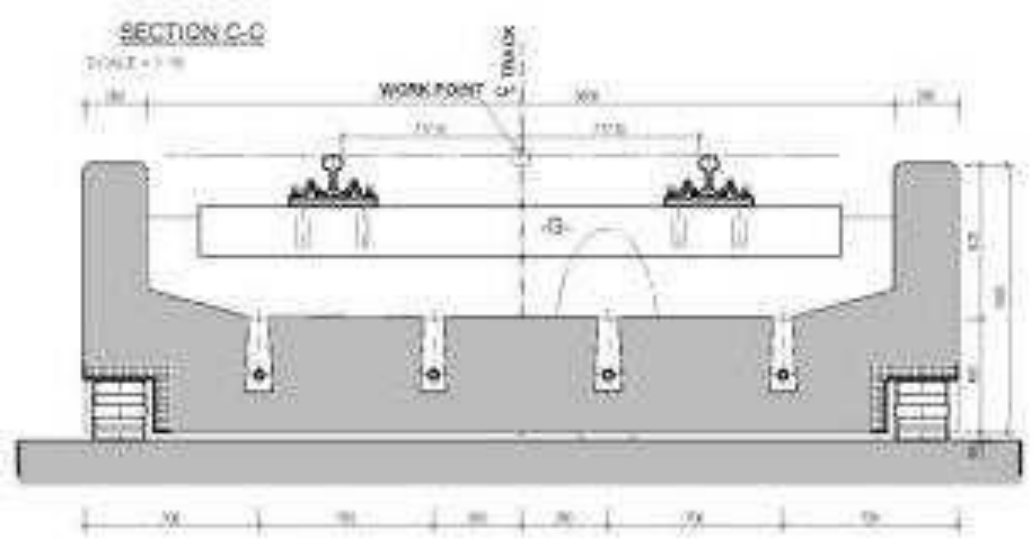

5. KY vibro-isolators in the ballasted track surface (GERB)

A wide range of options for selecting the stiffness of springs gives the possibility of precise vibroisolation in the construction of track surfaces. The spring of the vibro-isolator is installed in the holes left in the reinforced concrete slab of the rail structure Fig. 6.

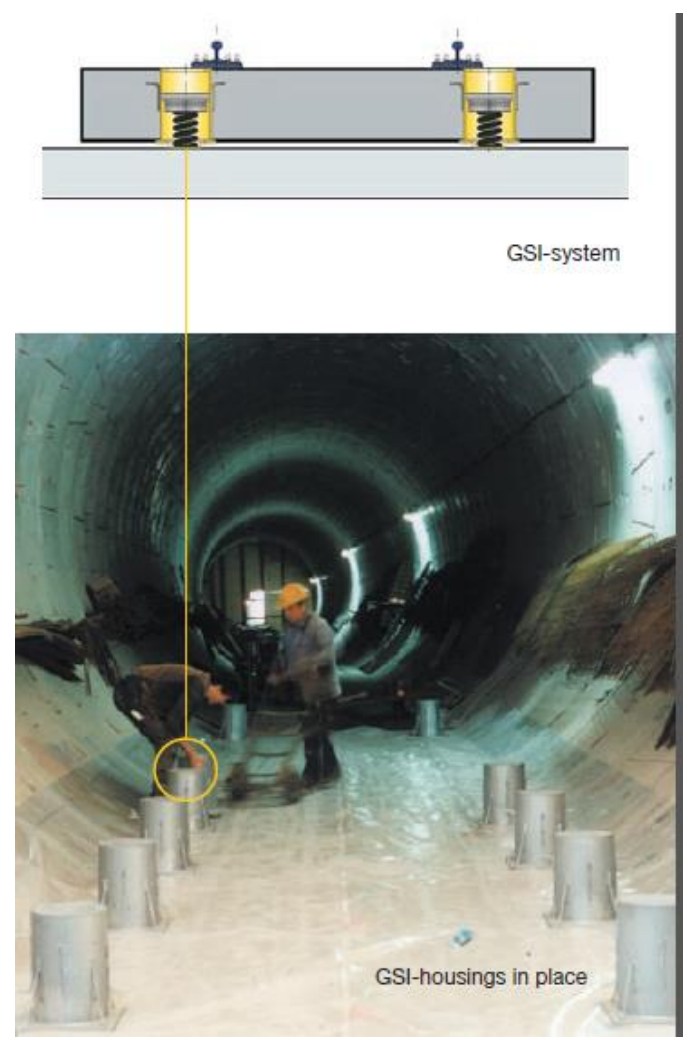

6. Calibration of the spring tension in the GSI muffler

Construction of the GSI spring vibro-isolator used in the construction of tracks is shown in section on Fig. 7. The applied vibration isolation in the form of spring damper gives the possibility of compensation (reduction of vibrations) displacements resulting from uneven settlement of the ground, which is particularly important in unfavorable geological conditions and mining damage areas. 


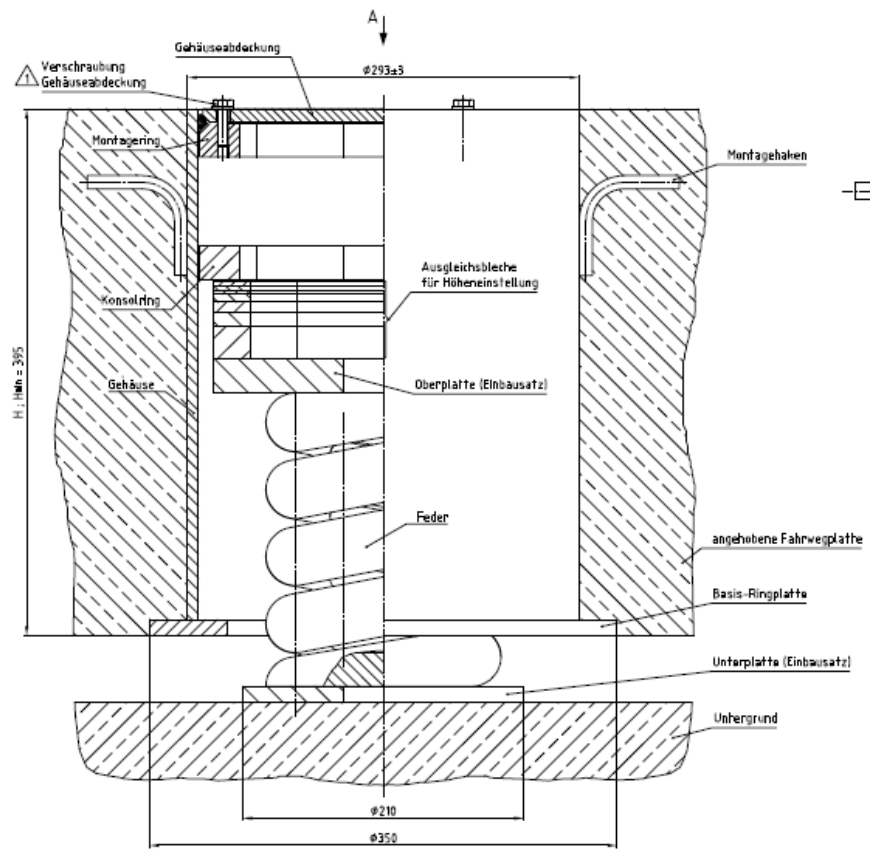

7. Construction of the GSI type vibro-isolator

Field studies on the example of a metro line

Track structures with spring-loaded vibroinsulation are used on tramway tracks, railways and in metro lines. In order to evaluate the impact of their application in the track construction, many operational tests were carried out.

The results of research conducted on the Shanghai metro line are presented below [1]. The research was carried out on the metro line no. 10 opened in 2010, on which the GERB Floating Slab Track (FST) spring-loaded vibroinsulating system was applied. Fig. 8 shows the diagram of the Shanghai metro line with the location of the test stand. 


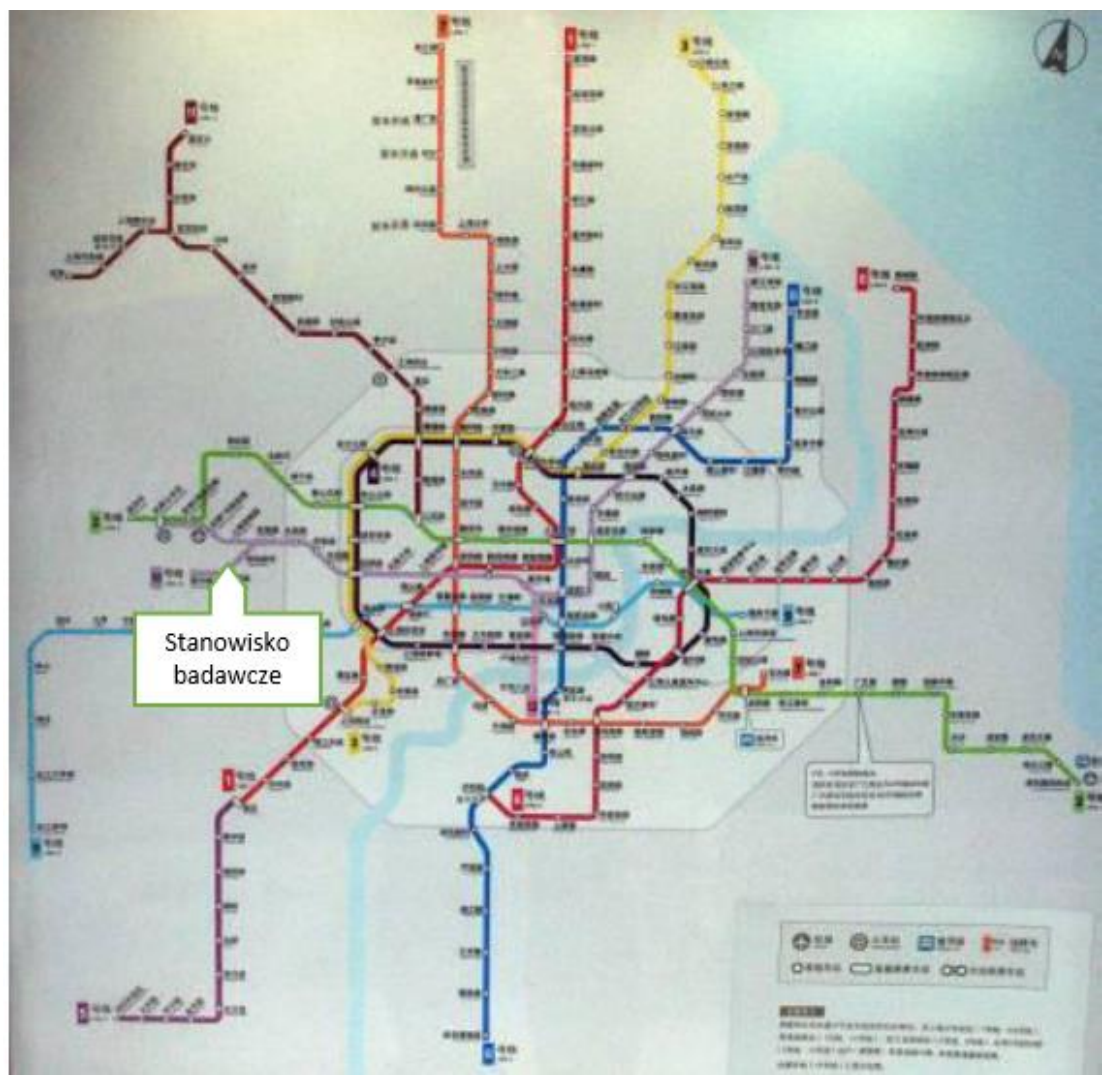

8. A subway diagram in Shanghai with the location of the test stand marked on line No. 10 (purple line))

The conducted research was carried out on two sections of the metro line No. 10, the first track section was located on a classic non-heap surface with fastening of rails on block supports (Fig. 9), the second measuring section was located on a track equipped with spring vibro-isolators Fig. 10.

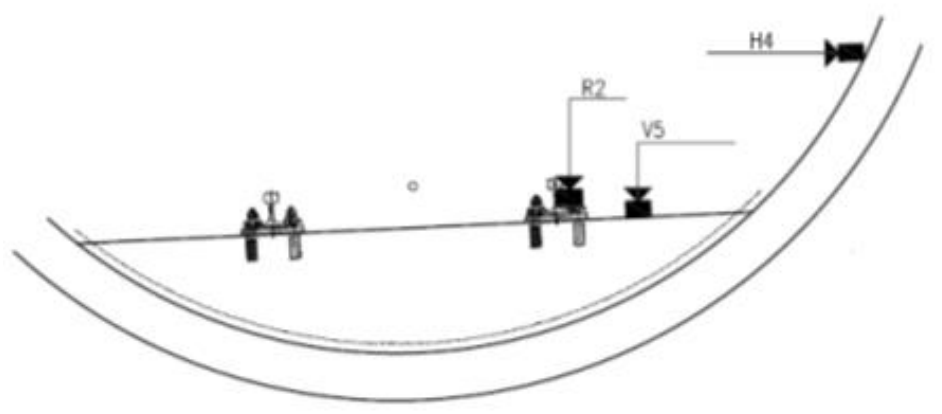

9. Scheme of a non-heap surface without springs with marked measuring points V2, $\mathrm{R} 1, \mathrm{~V} 1, \mathrm{H} 1$ 


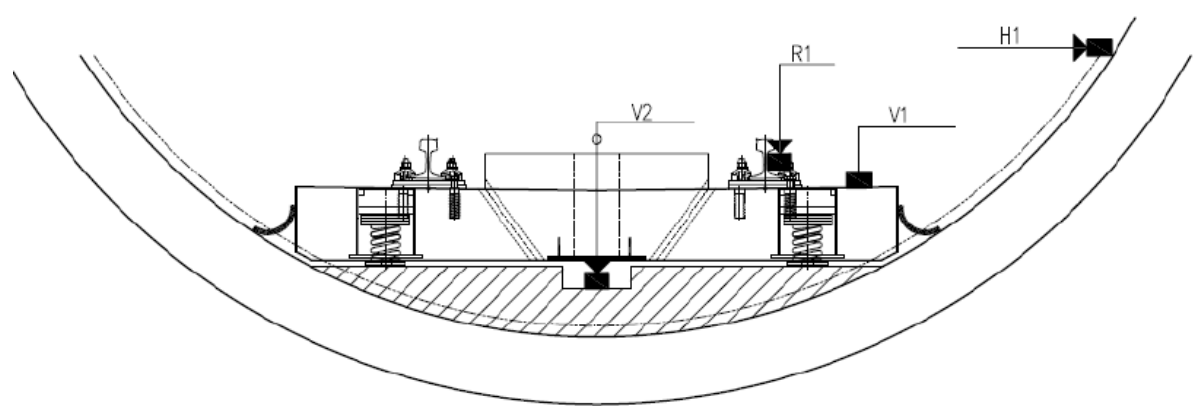

10. Scheme of a non-disintegrating surface with spring-loaded vibration isolation with marked measuring points $\mathrm{V} 2, \mathrm{R} 1, \mathrm{~V} 1, \mathrm{H} 1$

The distance between the test sections was $90 \mathrm{~m}$, which enabled simultaneous measurement of the vibrations generated by the passing train. The tests were of comparable nature and were aimed at assessing the impact of using spring vibroinsulation on the reduction of vibrations generated by a passing train and transferred to the surface and walls of the metro tunnel. Measurement sensors recording vibrations were located at four points marked: V2 track, R1 - on the rail, V1 - on the silencer on the concrete slab, H1 - on the tunnel wall. The location of the sensors is shown in Fig. 9 and Fig. 10. Mounting the sensors on a concrete slab is shown in Fig. 11.

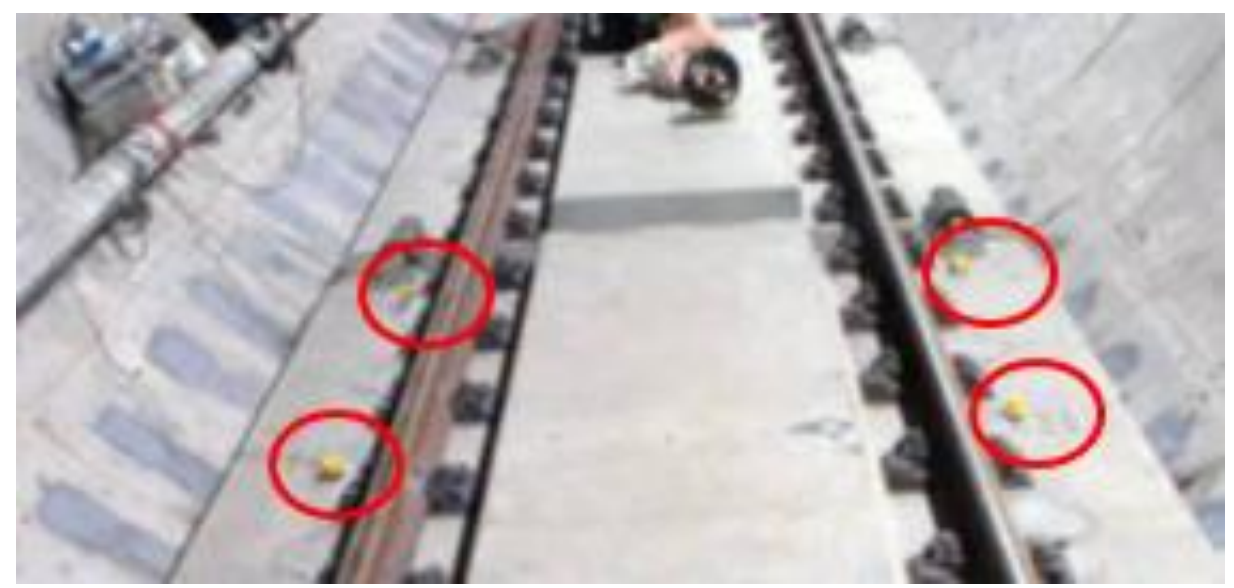

11. Location of measuring sensors on a concrete slab with a spring vibration isolation system on the metro line No. 10 in Shanghai.

Fig. 12 presents the waveforms of recorded vibration velocities on the walls of the tunnel structure for non-heap surfacing fitted with GSI type vibro-isolators. The results are presented as a function of the train travel time at $75 \mathrm{~km} / \mathrm{h}$. The maximum recorded vibration speed on the tunnel wall was $0,3 \mathrm{~mm} / \mathrm{s}$.

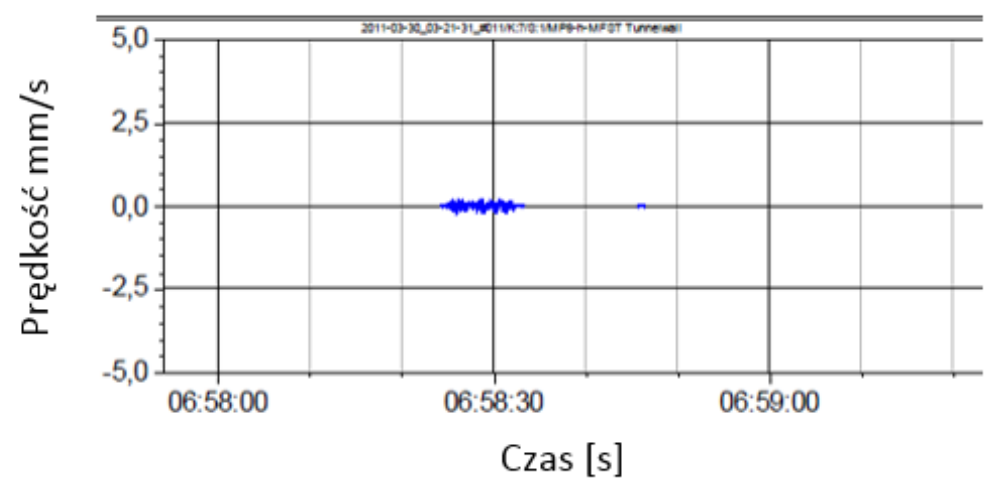


12. Sample results of the measurement of the speed of the recorded signal as a function of time for sensors located on the walls of the underground tunnel - surface with silencers.

Fig. 13 presents the results of measurements of vibration velocities registered on the tunnel wall at the passage of a subway train at a speed of $75 \mathrm{~km} / \mathrm{h}$ for a classic track surface of the under-bed type without spring-loaded vibration isolation. The maximum recorded amplitude of vibration velocity was $4,9 \mathrm{~mm} / \mathrm{s}$.

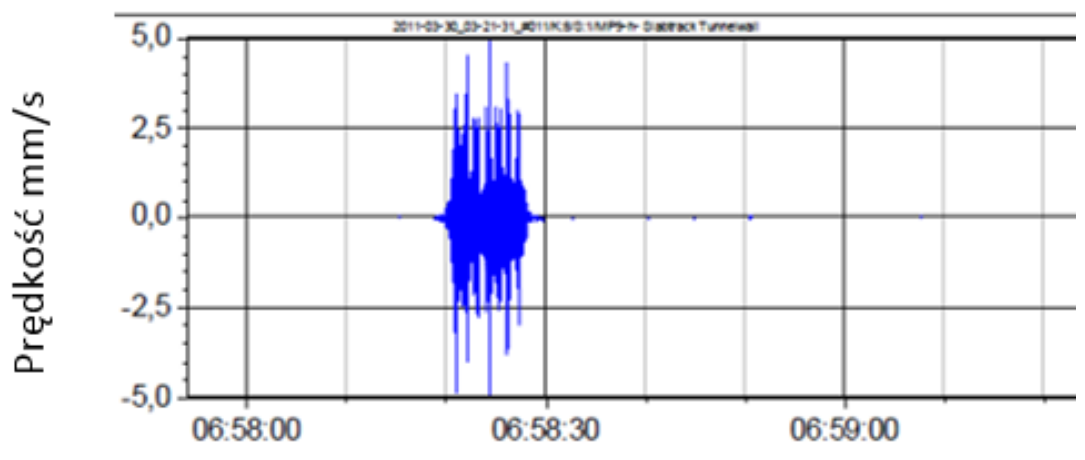

\section{Czas [s]}

13. Sample results of vibration velocity measurement in time function for sensors located on the walls of the underground tunnel - surface without spring damper

For the series of tests carried out, the level of vibration dampening expressed in $\mathrm{dB}$ was developed. The results of vibration damping tests are shown in Fig. 14 for two tested track structures. The level of damping depends on the range of the load generated by the passing train. The speed of the train on the test section of the metro line was $75 \mathrm{~km} / \mathrm{h}$.

The test results presented in Fig. 14 show the reduction of vibrations using spring dampers in the range above $10 \mathrm{~Hz}$ of the generated load. As a result of using spring vibroisolators in a non-dirt track surface, a vibration reduction of up to $28 \mathrm{~dB}$ was achieved compared to a surface without spring vibro-isolators.

The surface with spring vibration isolation can be used in track constructions in urban areas, i.e. in the vicinity of railway lines from historic architecture and for buildings, for which exact protection of their structure against vibrations is required also in the lowfrequency range. 


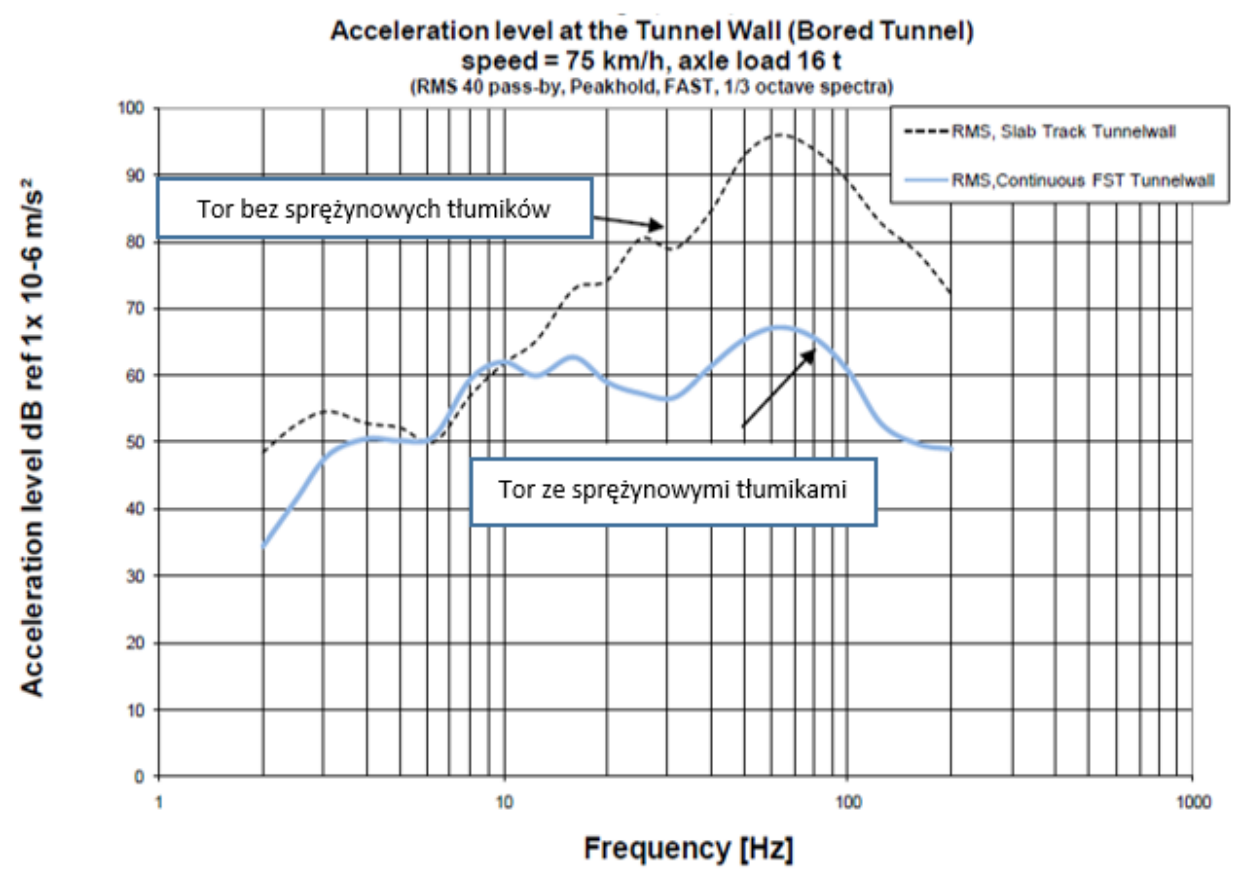

14. List of the values of the vibration level recorded on the tunnel wall at $\mathrm{H} 1$ for the tunnel surface with a concrete slab without spring vibration isolators and tunnel surface with spring vibration isolators.

\section{Summary}

The presented solutions of spring vibro-isolation of tracks can be applied wherever high efficiency is needed in the elimination of vibrations transmission from tracks to buildings and engineering structures. They are often used especially on sections of tracks in, for example, meters, in railway and tram lines in very sensitive situations, where the distances from buildings are very small. The given method of vibration isolation is a certain alternative to the known methods of vibration isolation, e.g. with the help of damping mats, and its importance increases in the aspect of the creation of railway lines with speeds above $250 \mathrm{~km} / \mathrm{h}$ and in urban areas on tram and rail lines.

Spring vibro-isolation is characterized by high durability, easy and economical assembly, high efficiency in the low frequency range and the possibility of adjusting e.g. in the case of ground subsidence.

\section{Source materials}

[1] Wagner, H.G.: Attenuation of Vibrations and Ground Borne Noise by means of steel spring supported low-tuned floating track bed, 2002 World Metro Symposium, Taipeh

[2] Wagner, H.G.; Herrmann, A.: Floating Slab Track above ground for turnouts in tram lines, 2007, Noise and Vibration Mitigation for transportation systems 